\title{
Determination of Thermophysical Properties for Selected Molding Sands
}

\author{
M. ŁĄGIEWKA* \\ Częstochowa University of Technology, Faculty of Production Engineering and Materials Technology, \\ Institute of Metallurgy and Metals Technology, Częstochowa, Poland
}

(Received August 26, 2019; revised version October 1, 2019; in final form October 2, 2019)

\begin{abstract}
This article presents results of the research, which allowed to study the main thermophysical properties of the oil-bonded molding sand and bentonite, i.e., the temperature equalization coefficient $a_{2}$ and the heat accumulation coefficient $b_{2}$ in the selected points of the casting mold. The method used to determine the coefficients $a_{2}$ (thermal diffusivity) and $b_{2}$ by measuring the temperature of the mold, allows simple and accurate calculation of these coefficients. The coefficients of heat transfer $\alpha_{1}$ and heat accumulation in molding $b_{2}$ state the ability to remove heat from the casting. As the volume (mass) of the mold increases, the amount of heat accumulated in the mold increases. Affecting the value of these indicators by selecting the composition of the molding sand and the method of preparing the mold for flooding, the heat flow rate from cast to mold can be regulated to a certain extent, i.e., affect the rate and time of solidification of the cast, which can have an obvious impact on the structure and properties of the cast. Based on the conducted tests, it was found that the values of coefficient $b_{2}$ differ from the value of this coefficient calculated on the basis of literature data, which allows to state that the theoretical calculation of the heat storage coefficient of molding sand is not sufficient and reliable and that these calculations should be verified experimentally.
\end{abstract}

DOI: 10.12693/APhysPolA.136.992

PACS/topics: theoretical basis of casting processes, molding material, oil binder, heat accumulation coefficient for molding sands, temperature equalization coefficient

\section{Introduction}

By proper selection of molding materials with appropriate properties, we can influence primarily the rate of heat removal from the casting to the mold [1]. The properties of molding materials are changed with the temperature change, so that the thermal conductivity, the specific heat value, and even the material density undergo changes. Therefore, the average (effective) values of the thermophysical properties should be used for calculations $[2,3]$. These effective values have to be determined experimentally, since the calculation methods are still lacking. The lack of analyses presenting calculations with respect to the properties of molding materials is due to the fact that each mass component has different properties. The mechanism of heat transfer through the sand mold is complex. It includes heat transfer through a single grain, heat transfer between neighboring grains, and intercrystalline exchange of heat by radiation and convection $[3,4]$.

The most important thermophysical properties related to the heat transfer between the casting and the mold are [2]: the thermal conductivity $\lambda$, the specific heat $c$, the thermal diffusivity $a_{2}$, the heat accumulation coefficient $b_{2}$, and the metal/mold interfacial heat transfer coefficient $\alpha_{1}$. Two of the above listed parameters are

\footnotetext{
*e-mail: lagiewka.malgorzata@wip.pcz.pl
}

of particular importance as far as the calculations concerning the cooling and the solidifying of castings in sand molds are regarded, both being the complex thermophysical coefficients: the heat accumulation coefficient $b_{2}$, and the thermal diffusivity $a_{2}$.

How quickly molding sand dissipates heat from the casting is indicated by two properties of the molding sand: the interfacial heat transfer coefficient $\alpha_{1}$ and the heat accumulation factor $b_{2}$.

The greater the amount of molding sand, the more heat it can accumulate. The heat accumulation coefficient is mainly characterized by the mold's ability to store heat at a given time; the higher the value, the more the form accumulates heat at a given time $[2-5]$.

The heat accumulation coefficient of a molding material is not a constant, but it changes with change in the temperature, mainly due to the temperaturedependent changes in thermal conductivity.

The heat accumulation factor for the molding materials can be determined in many ways, including by measuring the solidification time of the casting. For this measurement, the wall thickness of the casting must be much smaller than the thickness of the molding material around the casting. The thermocouple is mounted in the central part of the casting and the temperature of the potting must be as low as possible. Measurement of temperature in time leads to determining the solidification time of the casting [5-10]. Assuming that the form is half-space, the casting is devoid of internal thermal resistance, ignoring the impact of the shrinkage gap on the cooling and solidification process of the cast in the mold, 
knowing the solidification time of the casting, one can determine the coefficient $b_{2}$ from the Eq. (1):

$$
b_{2}=\frac{\sqrt{\pi} R_{1} \rho L_{m}}{2 v_{k r} \sqrt{\tau_{k}}},
$$

where $R_{1}$ is the relative wall thickness of the casting (in $\mathrm{m}$ ),$\rho$ is metal density (in $\mathrm{kg} / \mathrm{m}^{3}$ ), $L_{m}$ is heat of metal solidification (in $\mathrm{J} / \mathrm{kg}$ ), $\vartheta_{k r}=T_{k}-T_{2 p}$ (the contact temperature at the metal/mold interface minus the initial temperature of the mold (in $\mathrm{K})$ ), and $\tau_{k}$ is time of complete solidification of the casting (in $\mathrm{s}$ ).

A similar experiment can serve also to determine thermal diffusivity $a_{2}$ on the basis of the recorded mold temperature [9]. The thermal diffusivity is determined by the following expression:

$$
a_{2}=\frac{\lambda_{2}}{c_{2} \rho_{2}},
$$

where $\lambda_{2}$ is thermal conductivity of the molding material (in $\mathrm{W} /(\mathrm{m} \mathrm{K})), c_{2}$ is the specific heat of the molding material (in $\mathrm{J} /(\mathrm{kg} \mathrm{K})$ ) and $\rho$ is the density of the molding material (in $\mathrm{kg} / \mathrm{m}^{3}$ ).

The coefficient $a_{2}$ occurs, as well as $b_{2}$, in equations describing the transient heat flow and characterises the material ability to level the temperature over its volume. However, between $a_{2}$ and $b_{2}$ various thermophysical properties exist, and the following dependencies apply:

$$
\begin{aligned}
& \lambda_{2}=b_{2} \sqrt{a_{2}}, \\
& c_{2}=\frac{b_{2}}{\sqrt{a_{2} \rho_{2}}} .
\end{aligned}
$$

Another known method of finding the value of thermal diffusivity is the method of "pouring out". Liquid metal is poured into the mold, and after a certain time the metal, which has not solidified, has been poured. The solidified casting is removed from the mold. The thickness of the casting is then measured, and the factor $b_{2}$ is calculated from the formula $[4-7,10]$.

\section{Methods and results of investigation}

The purpose of investigation was the determination of some thermophysical properties of different molding materials: the conventional molding sand and the oilbonded molding sand of trade name O.B.B. SAND "E". The presented article presents the results of test coefficients of thermal diffusivity $a_{2}$ and heat accumulation $b_{2}$ of these materials. The numerical data for calculations were obtained from the experimental recording of temperature fields arising in the prepared molds during the solidification of the CuSi3Zn3Mn1 alloy of known solidification heat $L$ and specific heat $c$. The alloy is the corrosion-resistant bronze of good castability and good resistance to changing load, impact load, and abrasion, used for machine parts and construction parts (bearings, drive system elements) subjected to corrosion, irregular load, and poor lubrication [11-14].
In this work a research stand was used to measure temperature fields in sand molds made from the tested molding materials. The CuSi3Zn3Mn1 alloy was gravity cast at $1025^{\circ} \mathrm{C}$. One of the molds was made of the conventional bentonite bonded sand of the following composition: silica sand $-88 \%$, bentonite $-10 \%$, water $-2 \%$, while the other were made of the material with the trade name O.B.B. SAND "E". This mass is natural sand molding with an oil binder (grain size AFS No. 140 and average grain size equal to $0.09 \mathrm{~mm}$, compressive strength $1200 \mathrm{~g} / \mathrm{cm}^{2}$, shear strength $\left.380 \mathrm{~g} / \mathrm{cm}^{3}\right)$. Appropriate permeability and fluidity of the oil mass provide excellent dimensional accuracy of castings. The change in temperature over time during solidification and cooling of the metal was measured using a PCL-818 computer lab card. The temperature measurement took place every $0.01 \mathrm{~s}$. $\mathrm{NiCr}-\mathrm{Ni}$ thermocouples were used for the measurement [15-17].

The pattern for reproducing the mold cavity was a slab of dimensions $300 \times 200 \times 15 \mathrm{~mm}^{3}$. After making the mold and taking out the model, the thermocouples were placed in the following way: first in the center of the casting $x_{0}$, second in the cast/mold border $x_{1}$, while another 6 thermocouples in a distance of $5 \mathrm{~mm}$. Both molds were prepared and equipped in the same way. Then the pouring operation was performed. The measurement of the distribution of thermocouples in the mold is that after the temperature measurement is finished, the upper half of the mold is removed. Molding sand is removed from the lower half of the mold carefully with thin layers until the nearest thermocouple is exposed. After unveiling the weld, the distance between the axis of the weld and the contact surface is measured.

After recording the temperature fields for both test molds during the solidification of the model castings, it was possible to calculate their thermal diffusivities $a_{2}$ from the formula presented beneath:

$$
a_{2}=\frac{x^{2}}{4 \tau}\left(\arg \operatorname{erfc} \frac{T_{x}-T_{2 p}}{T_{k}-T_{2 p}}\right)^{-2} .
$$

The symbols here are defined as follows: $x$ - the distance of a thermocouple from the casting surface (in $\mathrm{m}$ ), $\tau$ - time elapsed from the moment of metal pouring (in s), $T_{x}$ - the temperature recorded at the distance $x$ at the time $\tau$ (in ${ }^{\circ} \mathrm{C}$ ), $T_{2 p}$ - the initial temperature of the mold (in ${ }^{\circ} \mathrm{C}$ ), $T_{k}$ - the contact temperature at the metal $/$ mold interface $\left(\right.$ in ${ }^{\circ} \mathrm{C}$ ).

Calculations were performed for the initial mold temperature of $20^{\circ} \mathrm{C}$, and the temperatures recorded by thermocouples at four selected points of time: 150, 300, 450 , and $600 \mathrm{~s}$ from the metal pouring. Table I compares, for the purpose of illustration, temperature values recorded at the metal $/$ mold interface $\left(T_{k}\right)$ for both examined molding sands.

The calculated values of average thermal diffusivity $a_{2}$ (in $\mathrm{m}^{2} / \mathrm{s}$ ) are: for conventional molding sand $5.54 \times 10^{-7}$ and for O.B.B. SAND "E" molding material $5.39 \times 10^{-7}$. 
TABLE I

Values of the temperature $T_{k}$ in ${ }^{\circ} \mathrm{C}$ recorded for the examined molding materials after the selected periods of time

\begin{tabular}{l|c|c|c|c}
\hline \hline \multirow{2}{*}{$\begin{array}{c}\text { Type of molding material } \\
\end{array}$} & \multicolumn{4}{|c}{$\begin{array}{c}\text { Time elapsed } \\
\text { from the moment } \\
\text { of metal pouring [s] }\end{array}$} \\
\cline { 2 - 5 } & 150 & 300 & 450 & 600 \\
\hline conventional molding sand & 572 & 365 & 270 & 207 \\
O.B.B. SAND "E" molding material & 668 & 507 & 405 & 335
\end{tabular}

Next, the value of the most important thermophysical property was calculated, namely the heat accumulation coefficient $b_{2}$. This coefficient is used in equations describing solidification and cooling of a casting in a mold. It is defined by the formula:

$$
b_{2}=\sqrt{\lambda_{2} c_{2} \rho_{2}}
$$

where $\lambda_{2}$ is the thermal conductivity of molding sand (in $\mathrm{W} /(\mathrm{m} \mathrm{K})), c_{2}$ is the specific heat of molding sand (in $\mathrm{J} /(\mathrm{kg} \mathrm{K})$ ) and $\rho_{2}$ is density of molding sand (in $\mathrm{kg} / \mathrm{m}^{3}$ ).

Note that Eq. (3) which relates $\lambda$ to the already calculated thermal diffusivity $a_{2}$, can be transformed to the form: $\lambda_{2}=a_{2} \rho_{2} c_{2}$. Substituting the latter into Eq. (6) one arrives to formula of the heat accumulation coefficient:

$$
b_{2}=c_{2} \rho_{2} \sqrt{a_{2}} .
$$

Now, taking into account the already known average value of $a_{2}$, the average value of the heat accumulation coefficient $b_{2}$ can be calculated. Thus, the resulting values of $b_{2}$ are: $1140.95 \mathrm{~W} \mathrm{~s}^{1 / 2} /\left(\mathrm{m}^{2} \mathrm{~K}\right)$ for conventional molding sand, and $1303.85 \mathrm{~W} \mathrm{~s}^{1 / 2} /\left(\mathrm{m}^{2} \mathrm{~K}\right)$ for O.B.B. SAND "E" molding material.

The heat accumulation coefficient can be also calculated theoretically on the basis of the available published data. The value obtained from Eq. (6) on the basis of data published in professional literature $[1,2]$ for the conventional molding sand is equal to $b_{2}=792.85 \mathrm{~W} \mathrm{~s}^{1 / 2} /\left(\mathrm{m}^{2} \mathrm{~K}\right)$ for the assumed theoretical values $\lambda_{2}=0.41 \mathrm{~W} /(\mathrm{m} \mathrm{K}), c_{2}=1029 \mathrm{~J} /(\mathrm{kg} \mathrm{K})$, $\rho_{2}=1490 \mathrm{~kg} / \mathrm{m}^{3}$.

The theoretical value of the heat accumulation coefficient calculated for the oil-bonded material is equal to $b_{2}=1037.24 \mathrm{~W} \mathrm{~s}^{1 / 2} /\left(\mathrm{m}^{2} \mathrm{~K}\right)$. for the assumed theoretical values $\lambda_{2}=0.58 \mathrm{~W} /(\mathrm{m} \mathrm{K}), c_{2}=1138 \mathrm{~J} /(\mathrm{kg} \mathrm{K})$, $\rho_{2}=1630 \mathrm{~kg} / \mathrm{m}^{3}$.

The value of the heat accumulation coefficient calculated from the theoretical data published in professional literature differs significantly from the value calculated on the basis of measurements of temperature in the form, both for the conventional bentonite-bonded molding material and for the oil-bonded one. For the oil-bonded material the difference reaches $20 \%$, while for the conventional one it rises even to about $30 \%$.

The value of the heat accumulation coefficient, as it was mentioned before, characterizes the molding material ability to absorb the heat emitted by a metal casting during its solidification and cooling. Formula (6) indicates that this coefficient increases non-linearly with an increase in thermal conductivity, the specific heat, and the density of the molding material. Figures 1 and 2 illustrate how the average value of the heat accumulation coefficient changed with the distance from the metal $/ \mathrm{mold}$ interface.

Figure 1, concerning the bentonite bonded sand, shows that the value of the heat accumulation coefficient is at the level of about $1050 \mathrm{~W} \mathrm{~s}^{1 / 2} /\left(\mathrm{m}^{2} \mathrm{~K}\right)$ for the distances up to $20 \mathrm{~mm}$ from the metal/mold interface, then increases and reaches the value of about $1350 \mathrm{~W} \mathrm{~s}^{1 / 2} /\left(\mathrm{m}^{2} \mathrm{~K}\right)$ at the distance of $30 \mathrm{~mm}$. Figure 2, presenting data for the O.B.B. SAND "E" molding material, exhibits also the stable value of $b_{2}$ for the distances

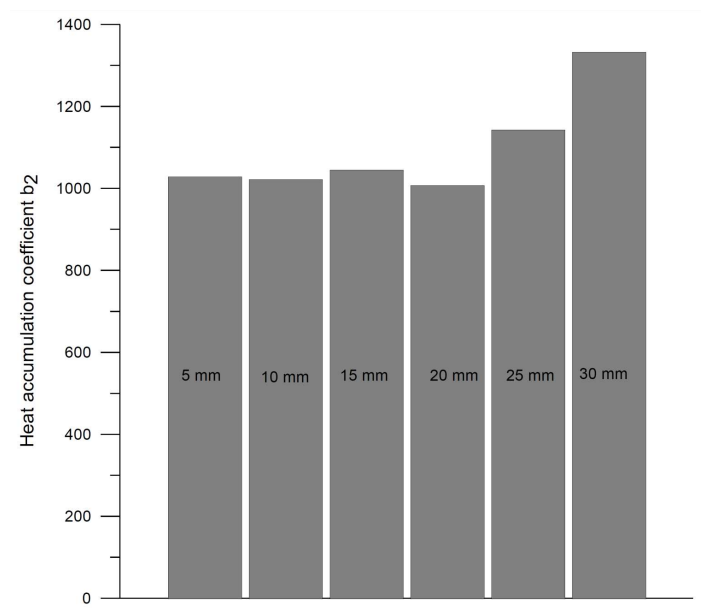

Fig. 1. Change in the heat accumulation factor for the bentonite mass at the tested distances from the metal/mold interface.

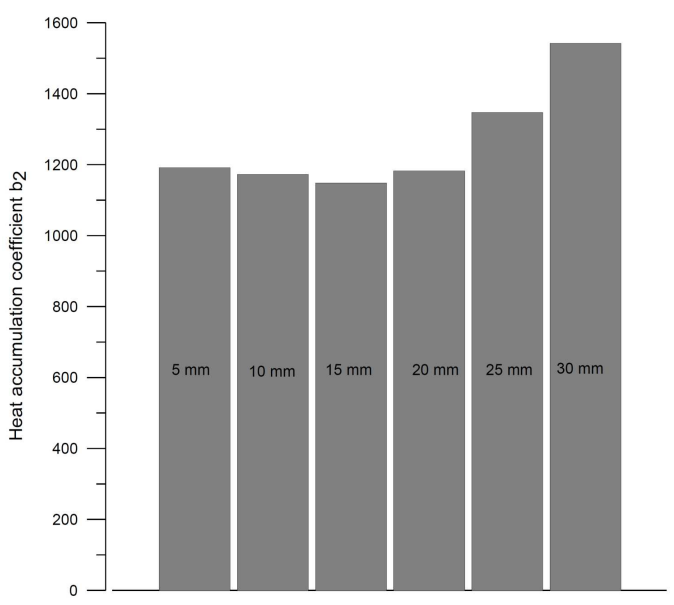

Fig. 2. Change in the heat accumulation factor for the oil bonded mass at the tested distances from the metal/mold interface. 
up to $20 \mathrm{~mm}$, being equal to about $1150 \mathrm{~W} \mathrm{~s}^{1 / 2} /\left(\mathrm{m}^{2} \mathrm{~K}\right)$, and the subsequent increase in the $b_{2}$ value reaching about $1550 \mathrm{~W} \mathrm{~s}^{1 / 2} /\left(\mathrm{m}^{2} \mathrm{~K}\right)$ at the distance of $30 \mathrm{~mm}$ from the metal $/$ mold interface.

\section{Conclusions}

The following conclusions can be drawn on the basis of the performed experiment and the analysis of its results:

1. The rate of solidification and the casting solidification time can be influenced by changing the values of $a_{2}$ and $b_{2}$ coefficients, so that the desirable changes in structure and properties would be achieved.

2. The values of $a_{2}$ and $b_{2}$ coefficients can be influenced by the proper selection of molding material composition.

3. The O.B.B. SAND "E" molding material is characterised by greater values of $a_{2}$ and $b_{2}$ coefficients than the conventional bentonite bonded sand, i.e., the oil-bonded O.B.B. SAND 'E' material exhibits greater heat accumulation capacity.

4. Theoretical calculations based entirely on the material data available in professional literature are not sufficient and can lead to mistakes; they should be verified experimentally in order to achieve reliable results.

5 . The applied method of determination of the $b_{2}$ coefficient allows for convenient and sufficiently exact performing of calculations.

6. Further improvement of the presented method of determination of the thermophysical parameters of molding materials and its measuring techniques seems reasonable in order to provide production of the flawless castings of high properties.

\section{References}

[1] J. Braszczyński, Theory of Casting Processes, PWN, Warsaw 1989 (in Polish).

[2] L. Lewandowski, Materials for Foundry Moulds, Akapit, Cracow 1997 (in Polish).

[3] W. Longa, Solidification of Castings, Śląsk, Katowice 1985 (in Polish).

[4] O. Ajibola, D. Toyin, B. Adewuy, Int. J. Met. 13, 1 (2015).

[5] S. Mahipal, B. Manjinder, S. Rohit, A. Hitesh, Int. J. Sci. Eng. Res. 4, 1497 (2013).

[6] P. Jelonek, T. Elbel, Archiv. Foundry Eng. 10, 77 (2010).

[7] Z. Ignaszak, Thermophysical Properties of Moulding Materials in Terms of Controlling the Casting Solidification Process, Ed. of Poznan University of Technology, Poznań 1989 (in Polish).

[8] Z. Pawłowski, M. Krobot, J. Zuber, in: Proc. 11th Scientific Symp. of AGH, Cracow, 1985, Technical University in Cracow (in Polish).

[9] K. Bala, R. Khan, Int. J. Eng. Res. Technol. 2, 83 (2013).

[10] B. Borowiecki, Krzepnięcie Metali i Stopów 30, 35 (1997) (in Polish).

[11] J.S. Kowalski, "Technological Aspects of Temperature-Induced Transitions of Silica Sand Matrix of the Synthetic Moulding Material Containing Bentonite", Monograph 394, Cracow University of Technology, 2011 (in Polish).

[12] E.P. DeGarmo, R.A. Kohser, Materials and Processes in Manufacturing, Wiley, New York 2010.

[13] C.A. Santos, J.M.V. Quaresma, A. Garcia, J. Alloys Comp. 319, 174 (2001).

[14] H.M. Sheidi, Res. J. Eng. Appl. Sci. 1, 404 (2012).

[15] Z. Konopka, M. Łacgiewka, Hutnik (The Metallurgist) 6, 285 (2006) (in Polish).

[16] M. Łągiewka, Archiv. Foundry Eng. 11, 33 (2011).

[17] M. Łagiewka, Z. Konopka, A. Zyska, M. Nadolski, Archiv. Foundry Eng. 13, 123 (2013). 